\title{
Ensino de ciências e matemática na Amazônia Legal: o processo de definição dos conceitos da abordagem na educação do campo
}

\section{Teaching Science and Mathematics in the Amazon: the process of defining the concepts in the approach of rural education}

Eduardo Ribeiro Mueller ${ }^{1}$ Geison Jader Mello ${ }^{2}$ Valdenor Santos Oliveira ${ }^{3}$
1 Mestre em Educação. Professor do Curso de Química da Universidade Federal de Mato Grosso - Campus Araguaia.

2 Doutorando em Física Ambiental. Professor do Curso de Física do Instituto Federal de Mato Grosso - Campus Fronteira Oeste.

3 Mestre em Educação. Professor do Centro de Formação de Professores - Secretaria de Estado de Educação de Mato Grosso.

\section{Resumo}

Este trabalho trata de uma proposta de aulas de Ciências da Natureza e Matemática, envolvendo as disciplinas de Matemática, Biologia e Química, nas quais a condição de ensinar estabeleceu importante subordinação à realidade como contexto de estudo. Seu relato aqui, embora não traga mais que uma experiência didática escolar, compartilha uma escola capaz de pensar, planejar, intervir, diagnosticar problemas e propor soluções em uma comunidade rural, assumindo seu papel de emancipadora, não abrindo mão do diálogo com os conceitos estruturantes das disciplinas envolvidas no estudo.

Palavras-chave: Pedagogia da alternância. Agricultura familiar. Interdisciplinaridade. Meio ambiente.

\begin{abstract}
This work is a proposal for classes of Natural Sciences and Mathematics, and it involves the disciplines of Mathematics, Biology and Chemistry, in which the condition to teach established important subordination to the reality as the context of study. The account of the paper, although does not bring more than a teaching experience, shares a school able to think, to plan, to intervene, to diagnose problems and to propose solutions in a rural community, assuming its role as empowering, not giving up dialogue with the structuring concepts of disciplines involved in the study.
\end{abstract}

Keywords: Pedagogy of the alternation. Family farming. Interdisciplinarity. Environment. 


\section{Introdução}

Este trabalho apresenta os resultados de pesquisa que foi desenvolvida junto à Escola Municipal Rural Minuano, município de Terra Nova do Norte - MT, localizada na Amazônia Legal. A região, conhecida como Portal do Amazonas, possui uma população marcadamente migrante do Estado do Rio Grande do Sul, em sua maioria pequenos proprietários rurais (MELLO, 2008).

Trabalhou-se com temas geradores por meio da Pedagogia da Alternância - forma pioneira de trabalho com temas geradores no Brasil (CESCON, 2005). Essa escola buscou a tematização da realidade local e, quando o estudo esteve voltado à "agricultura", promoveu debates com pais e alunos, fazendo emergir questões pautadas em educação crítica, dialógica (MORTIMER, 2000), que propõe ações coletivas como fomentadoras das mudanças sociais, econômicas e políticas do meio, indissociando teoria e prática no trabalho de formação.

Sem a intenção de discutir a Educação do Campo, seu percurso, suas metodologias, perspectivas, políticas de base educacionais, este artigo tem como objetivo socializar uma forma de abordagem de conceitos básicos das Ciências da Natureza e Matemática que, em um encontro contextual propício, gerou acomodações cognitivas provenientes de uma proposta de ensino, bem como crítica à realidade pelo fomento dado à problematização dos fenômenos envolvidos. Seu foco será mostrar como o contexto pode servir à aula, na escolha dos conceitos da abordagem, sem representar obviamente um basta, capaz de produzir aprendizagem somente a partir de si (desse contexto).

\section{Metodologia}

Para esta abordagem, a área de Ciências Naturais e Matemática, buscando atender ao tema "agricultura", dentro de suas particularidades, propôs-se, após ouvir os alunos, um projeto que debatesse e confrontasse a produção de maracujá (muitos pais de alunos possuem essa cultura como alternativa de renda, proveniente de incentivo de uma cooperativa local), observando como aspecto de confronto a produção com e sem o uso de agrotóxicos. "Como está se dando a produção de maracujá, de pequenos agricultores familiares de Terra Nova" foi o subtema de estudo da turma do $3^{\circ}$ ano do Ensino Médio, que tinha 13 alunos. Cada turma tinha o seu subtema de estudo, obviamente delimitado dentro do tema geral "agricultura".

Os professores promoveram inicialmente uma dinâmica, na qual todos os estudantes foram convidados a falar, confrontando o uso de agrotóxicos com a cultura orgânica, tendo a produção de maracujá dos seus sítios e de sítios vizinhos como instrumento de discussão. Essa dinâmica tinha como objetivo identificar abstrações (ou concepções prévias), medos e o envolvimento do aluno com a proposta, mas, sobretudo, suas perspectivas de investigação.

O resultado da dinâmica sozinha, no entanto, não conduziu à próxima etapa, que consistia, conforme planejamento inicial, em definir o universo mais adequado ao assento dos conceitos estruturantes das ciências dentro do tema. Optamos, então, por conduzir os estudantes a uma visita à cooperativa responsável pelo projeto do maracujá. Essa visita consistiu na coleta de dados sobre o plantio, os quais fossem capazes de nos subsidiar na decisão acerca de quais conceitos trabalhar. O ônibus escolar nos transportou da escola à cooperativa, distante $10 \mathrm{~km}$, onde protocolamos um ofício requisitando as informações ao presidente da entidade, as quais nos foram disponibilizadas no mesmo dia.

Uma nova etapa de coleta de dados sucedeu esse desafio, e ela seria realizada com os produtores. Passamos então ao próximo passo: elaborar roteiro de visita e entrevista com 32 produtores de maracujá das comunidades onde moravam os alunos. Essa amostra representava cerca de $27 \%$ de todos os produtores do município e foi escolhida pela facilidade de acesso, tendo em vista melhorar o deslocamento dos estudantes para a realização da visita.

As questões da entrevista foram pré-elaboradas pelos estudantes e por nós, professores da área, após pequena edição, dividindo-as em três grupos:

1a) Quanto ao uso da mão de obra na lavoura do maracujá (10 questões).

$2^{\text {a) }}$ Quanto ao aspecto econômico e assistência técnica da produção de maracujá (11 questões).

3a) Quanto à utilização de insumos agrícolas na produção de maracujá (12 questões). 
De posse das respostas, realizamos, com os alunos, o trabalho de sistematização dos resultados em tabelas, quadros, gráficos e textos. Os conteúdos da abordagem, enfim, foram escolhidos, após debates, nos quais professores e alunos julgaram o que seria pertinente ao universo dos conceitos de Ciências e Matemática que se pretendia conhecer.

Uma última visita foi realizada a um dos três produtores que não utilizavam agrotóxicos, para que os estudantes pudessem conhecer aspectos da produção orgânica. O trabalho, em sala de aula, com os conceitos estruturantes fechou a atividade.

\section{Resultados e discussão}

Em municípios do estado de Mato Grosso, como consequência das atividades extensivas do agronegócio (pecuária e soja), algumas pesquisas recentes indicaram a presença tanto de resíduos de inseticidas veterinários em leite bovino como de resíduos de agrotóxicos em leite materno (HERNANDES et al., 2009; PALMA, 2011). Esses poluidores, além de contaminar o ambiente, podem se acumular no organismo e causar agravos diversos à saúde humana como malformações, abortos, interferentes endócrinos e alguns tipos de câncer. Encontrar solução para esse problema de saúde pública é um grande desafio social e ressalta a necessidade de um ensino de Ciências Naturais e Matemática com abordagem interdisciplinar, ora por envolver áreas como saúde, agricultura, ciência e tecnologia, meio ambiente e trabalho (SIQUEIRA; KRUSE, 2008), ora porque, na busca de uma melhor qualidade de vida para a comunidade, “[...] toda a realidade está aí submetida à nossa possibilidade de intervenção nela" (FREIRE, apud NASCIMENTO, 2005, p. 38).

A dinâmica realizada criou um imbróglio para os professores quanto à condução das atividades dali em diante, dada a multiplicidade de sugestões, todas com potenciais perfis a abordagens no estudo. As opiniões sintetizadas pelos professores a partir do discurso de cada estudante, separadas por gênero, foram as seguintes:

Tabela 1- Opiniões das Alunas

\begin{tabular}{|c|c|}
\hline Alunas & Significado central extraído do discurso \\
\hline A1 & $\begin{array}{l}\text { Reconheceu ambas as técnicas de produção como importantes. Orgânica porque não agride a } \\
\text { saúde humana; com agrotóxicos porque maximiza a produção e diminui a mão de obra. }\end{array}$ \\
\hline $\mathrm{A} 2$ & $\begin{array}{l}\text { Relativizou, assim como } \mathrm{A} 1 \text {, demonstrando leve tendência à defesa do uso de agrotóxicos, admitindo } \\
\text { não conhecer aspectos da produção via controle biológico. }\end{array}$ \\
\hline $\mathrm{A} 3$ & $\begin{array}{l}\text { Demonstrou forte tendência à defesa dos orgânicos. Em sua fala lembrou-se da morte de animais } \\
\text { (insetos e micro-organismos) com o uso indiscriminado de agrotóxicos. }\end{array}$ \\
\hline A4 & $\begin{array}{l}\text { Demonstrou forte preocupação com a forma como os produtores de maracujá estavam conduzindo } \\
\text { suas pequenas lavouras. Muito tempo de trabalho; muito agrotóxico utilizado e pouco lucro. }\end{array}$ \\
\hline A5 & $\begin{array}{l}\text { Levantou o custo/benefício/saúde da produção de maracujá, pois os agrotóxicos utilizados eram } \\
\text { muito caros e ninguém havia orientado quanto à correta maneira de manuseá-los. Preocupação } \\
\text { com o próprio pai, que muitas vezes se queixava de dor de cabeça. }\end{array}$ \\
\hline A6 & $\begin{array}{l}\text { Sugeriu que buscássemos novas formas de manuseio de lavouras, as quais não necessitem do uso } \\
\text { de agrotóxicos. }\end{array}$ \\
\hline A7 & $\begin{array}{l}\text { Sugeriu que investigássemos o nível de "contaminação química" das lavouras de maracujá das } \\
\text { comunidades, tendo em vista a "alta" carga de agrotóxicos utilizados. }\end{array}$ \\
\hline A8 & $\begin{array}{l}\text { Aferiu perfil apolítico ao produtor de maracujá, que sequer conhecia a estrutura da cooperativa que } \\
\text { subsidiou o seu plantio e comprava seu maracujá. (Era preciso ser sócio para usufruir dos créditos } \\
\text { disponibilizados pela cooperativa. Assim, todos os produtores pesquisados eram sócios). }\end{array}$ \\
\hline A9 & $\begin{array}{l}\text { Apenas contou uma história sobre como um vizinho de sítio está arrependido de ter investido em } \\
\text { maracujá. }\end{array}$ \\
\hline
\end{tabular}

Fonte: Autores. 
Tabela 2 - Opiniões dos Alunos

\begin{tabular}{c|l}
\hline Alunos & \multicolumn{1}{c}{$\begin{array}{c}\text { Significado central extraído do } \\
\text { discurso }\end{array}$} \\
\hline A10 & $\begin{array}{l}\text { Lembrou que a renda do primeiro plantio } \\
\text { foi significante para sua família, mas que a } \\
\text { diminuição do valor do preço do quilo em } \\
\text { R\$0,20 (de R\$0,60 para R\$0,40), ocorrida } \\
\text { recentemente, poderia comprometer o } \\
\text { lucro agora, tendo em vista o aumento } \\
\text { do preço dos agrotóxicos e a perspectiva } \\
\text { ruim de chuvas. }\end{array}$ \\
\hline A11 & $\begin{array}{l}\text { Questionou, categoricamente, se seria } \\
\text { possível viver sem agrotóxicos. Ele não } \\
\text { acreditava que fosse possível. }\end{array}$ \\
\hline A12 & $\begin{array}{l}\text { Concordou com A11, concluindo com } \\
\text { a frase: "não tem mais jeito, tudo está } \\
\text { contaminado". }\end{array}$ \\
\hline A13 & $\begin{array}{l}\text { Para ele, talvez como resultado de todas } \\
\text { as falas, era preciso conhecer mais sobre } \\
\text { orgânicos. }\end{array}$ \\
\hline
\end{tabular}

Fonte: Autores.

As Tabelas 1 e 2 sugerem forte conflito com o universo do tema em estudo e apresentam estímulos ao ensino proposto. São opiniões que traduzem, pelos problemas que representam, sentimentos dos próprios estudantes, tais como indignação, preocupação, curiosidade, insegurança etc., sem os quais o alcance da crítica pela via da aprendizagem não seria possível. Como contribuição, o debate instaurou de vez o problema.

$\mathrm{Na}$ cooperativa de produtores, o ofício protocolado requeria, com texto que não especificava quais, informações que (nos) ajudassem a entender o processo evolutivo da cultura de maracujá sob a gestão daquela entidade. Essas informações constituíram um relatório técnico, cujo retrato nos levou, professores e alunos, a uma condição de interesse ainda mais acentuada pela questão.

Nesse relatório constavam gráficos que mostravam o comparativo entre número de produtores/visita técnica/número de técnicos; o quantitativo de beneficiários de financiamentos liberados em agropecuárias para o plantio de maracujá; o quantitativo de produtores do projeto de fruticultura, das safras 2005/2006, 2006/2007 e 2007/2008, dos quais fazem parte os produtores de maracujá; e a evolução da área de plantio do maracujá para o mesmo período.

Esses dados vieram corroborar com o sentimento de insatisfação externado pelos estudantes no início das atividades, pois mostraram queda relevante do número de produtores de uma safra para outra, mostraram número insuficiente de técnicos e de visitas técnicas, além de queda na área de plantio, o que sinalizava a ineficiência do projeto como alternativa de renda ao pequeno produtor.

Trazer os conceitos a esse cenário, extremamente favorável, mesmo não significando garantia de aprendizagem, representa a complementaridade do processo de ensino-aprendizagem pelo trabalho à estruturação de conceitos verdadeiros (VIGOTSKI, 2008), ou seja, aqueles possíveis de generalização por parte de quem aprendeu.

O penúltimo passo metodológico dado, de onde extraímos outros conceitos estruturantes das Ciências e Matemática nessa abordagem didática, resultou da interpretação das entrevistas com os produtores. Das 33 questões elaboradas e conduzidas pelas entrevistas, como instrumento de coleta de dados pelos alunos, produzimos uma síntese, na qual as questões de maior relevância foram trazidas à discussão, apresentadas a seguir:

$1^{\text {a) }}$ Quanto ao uso da mão de obra na lavoura do maracujá: Amostra de 10 agricultores.

A mão de obra é familiar, com 2,4 pessoas, em média, trabalhando 6,27 horas por dia, 19,7 dias por mês;

Segundo os produtores, toda a mão de obra disponível executa a maioria das atividades necessárias destaque para a polinização, que envolve quase $100 \%$ das pessoas que trabalham na lavoura;

95\% dos produtores admitiram receber uma pequena ajuda das mamangavas no trabalho de polinização;

$70 \%$ admitiram já ter encontrado essas abelhas mortas em seu plantio; 
Nenhum deles conhece os lugares onde as mamangavas têm seus ninhos.

2a) Quanto ao aspecto econômico e assistência técnica da produção de maracujá.

Cada produtor investiu, em média, $\mathrm{R} \$ 3.000,00$ (três mil reais) em seu primeiro plantio;

Mais de $90 \%$ admitiram ter recebido apoio técnico/financeiro da Coopernova para que tomasse a decisão de plantar;

Nos quatro primeiros meses de 2008, esses produtores colheram, em média, $1.567 \mathrm{~kg} /$ mês de maracujá, gerando assim uma renda média bruta de $\mathrm{R} \$ 627,00$ a cada 30 dias;

Quadro 1 - Adubos, citados de forma espontânea
Se considerarmos os 12 meses do ano, essa média baixa para $1.110 \mathrm{~kg}$, tendo em vista que há meses não produtivos, gerando uma renda média bruta de apenas $\mathrm{R} \$ 444,00$;

Apenas 9\% admitiram não ter recebido, ainda, visita do técnico da Coopernova;

$27 \%$ disseram estar arrependidos do investimento que fizeram no maracujá.

$3^{\mathrm{a})}$ Quanto à utilização de insumos agrícolas na produção de maracujá.

29 dos 32 produtores utilizavam adubo ou agrotóxico $(90,63 \%)$;

\begin{tabular}{|c|c|c|}
\hline ADUBOS CITADOS & $\begin{array}{c}\text { NÚMERO DE AGRICULTORES } \\
\text { QUE UTILIZAM }\end{array}$ & PERCENTUAL (\%) \\
\hline F 44 & 4 & 12,50 \\
\hline 25 & 4 & 12,50 \\
\hline ADUBO FOLIAR & 4 & 12,50 \\
\hline ESTERCO DE GADO & 4 & 12,50 \\
\hline NPK & 4 & 12,50 \\
\hline SULFATO DE COBRE & 1 & 3,13 \\
\hline 250025 & 14 & 43,75 \\
\hline 20020 & 7 & 21,88 \\
\hline ADUBO ORGÂNICO & 1 & 3,13 \\
\hline 20030 & 1 & 3,13 \\
\hline 17 & 1 & 3,13 \\
\hline UREIA & 4 & 12,50 \\
\hline $\mathrm{FH} 444$ & 1 & 3,13 \\
\hline FTE & 1 & 3,13 \\
\hline FERTILIZANTE & 1 & 3,13 \\
\hline SUPER FOSFATO SIMPLES & 1 & 3,13 \\
\hline CALCÁRIO FILLER & 1 & 3,13 \\
\hline
\end{tabular}

Fonte: Alunos do $3^{\circ}$ ano do Ensino Médio da Escola Municipal Minuano. 
O Quadro 1 mostra os tipos de adubos citados por 29 agricultores de maracujá. Vários desses produtores citaram mais de um tipo de adubo, especificando a

Quadro 2 - Agrotóxicos, citados de forma espontânea situação do uso (antes do plantio, no preparo da terra, durante o crescimento das plantas etc.).

\begin{tabular}{|c|c|c|c|c|}
\hline $\begin{array}{c}\text { AGROTÓXICOS } \\
\text { UTILIZADOS }\end{array}$ & $\begin{array}{c}\text { NÜMERO DE } \\
\text { AGRICULTORES } \\
\text { QUE UTILIZAM }\end{array}$ & \multicolumn{2}{c|}{$\begin{array}{c}\text { CUSTO NA } \\
\text { COOPERNOVA }\end{array}$} \\
\hline DUOS AGROTÓXICOS \\
\hline CUPROGARB & 13 & 40,63 & $\mathrm{R} \$ 28,00 / \mathrm{kg}$ & Fungicida \\
\hline FOLICUR & 12 & 37,50 & $\mathrm{R} \$ 88,50 /$ litro & Fungicida \\
\hline KARATE ZEON & 1 & 3,13 & $\mathrm{R} \$ 23,00 /$ litro & Inseticida \\
\hline LEBAYCID & 2 & 6,25 & $\mathrm{R} \$ 138,80 /$ litro & Inseticida/Acaricida \\
\hline VERTIMEC & 7 & 21,88 & $\mathrm{R} \$ 15,00 /$ litro & Óleo Mineral \\
\hline ASSIST & 7 & 21,88 & $\mathrm{R} \$ 65,00 /$ litro & Inseticida \\
\hline DECIS & 8 & 25,00 & $\mathrm{R} \$ 55,60 /$ litro & Fungicida/lnseticida \\
\hline CARTAP & 1 & 3,13 & $\mathrm{R} \$ 46,90 /$ litro & Fungicida \\
\hline DEROSAL & 1 & 3,13 & & \\
\hline
\end{tabular}

Fonte: Alunos do $3^{\circ}$ ano do Ensino Médio da Escola Municipal Minuano.

O Quadro 2 apresenta uma preferência pelos produtos Cuprogarb, Folicur, Decis, Vertimec e Assist. A escolha do produtor, na hora de comprar, foi justificada quase sempre pelo tripé preço/rendimento/resultado.

Quadro 3 - Responsabilidade do manuseio dos agrotóxicos na lavoura.

\begin{tabular}{|c|c|c|}
\hline $\begin{array}{c}\text { QUEM PASSA O AGROTÓXICO NA } \\
\text { LAVOURA DE MARACUJÁ? }\end{array}$ & RESPOSTA & 89,66 \\
\hline O PRÓPRIO PRODUTOR & 26 & 0,00 \\
\hline OUTRA PESSOA DA FAMÍLIA & 0 & 10,34 \\
\hline EMPREGADO & 3 & $\%)$ \\
\hline
\end{tabular}

Fonte: Alunos do $3^{\circ}$ ano do Ensino Médio da Escola Municipal Minuano.

O Quadro 3 confirma que a maior parte da mão de obra é familiar, pois, dos 3 empregados citados para a função de passar o agrotóxico, apenas 1 possuía vínculo empregatício com salário mensal. Os outros eram diaristas, designados apenas a essa função, ou seja, a de pulve- rizar o plantio com os defensivos agrícolas. Veja também que, quando o produtor não está disposto a assumir os riscos do manuseio, não os delega a ninguém de sua família (filho ou esposa). 
Quadro 4 - Sobre o lugar onde realiza compra do agrotóxico

\begin{tabular}{|c|c|c|}
\hline $\begin{array}{c}\text { ONDE COMPRA O AGROTÓXICO } \\
\text { QUE UTILIZA? }\end{array}$ & 29 & 100 \\
\hline COOPERNOVA & 0 & 0 \\
\hline OUTRO LUGAR & PUANTIDADE DE RESPOSTAS & PERCENTUAL (\%) \\
\hline $\begin{array}{c}\text { SEMPRE EXIGE NOTA FISCAL } \\
\text { QUANDO COMPRA O } \\
\text { AGROTÓXICO QUE UTILIZA? }\end{array}$ & QUANTIDADE DE RESPOSTAS & 100 \\
\hline SIM & 29 & 0 \\
\hline NÃO & 0 & PERCENTUAL (\%) \\
\hline $\begin{array}{c}\text { O LUGAR ONDE COMPRA SEU } \\
\text { AGROTÓXICO RECOLHE AS } \\
\text { EMBALAGENS VAZIAS? }\end{array}$ & QUANTIDADE DE RESPOSTAS & 100 \\
\hline SEMPRE & 29 & 0 \\
\hline ÀS VEZES & 0 & 0 \\
\hline NUNCA & 0 & \\
\hline
\end{tabular}

Fonte: Alunos do $3^{\circ}$ ano do Ensino Médio da Escola Municipal Minuano.

O Quadro 4 chama atenção à fidelidade que os produtores têm à cooperativa da qual são sócios e ao bom trabalho que essa entidade realiza como instituição responsável pelas embalagens de agrotóxicos que comercializa.

Esses e outros resultados abriram as possibilidades de abordagem a prováveis conceitos/conteúdos nas Ciências da Natureza e Matemática. Algumas questões foram postas em discussão e, ao final, os encaminhamentos dados por professores e alunos para aprofundamento foram:

$\left.1^{\circ}\right)$ A disciplina de Biologia seria contemplada com o estudo da abelha mamangava. Nesse estudo, os alunos deveriam realizar levantamentos que respondessem às seguintes questões:

Qual a taxonomia dessas abelhas?

Que nomes (populares e científicos) recebem?

Como se reproduzem?

Do que se alimentam?

Onde vivem (habitat)?

Quantos tipos diferentes de mamangavas existem?
Qual a provável relação (hipóteses) entre as abelhas encontradas mortas e a utilização de agrotóxicos nas lavouras pesquisadas?

Por que polinizam o maracujá?

Qual hora do dia estão polinizando?

$2^{\circ}$ ) A disciplina de Química seria contemplada com o estudo dos agrotóxicos citados. Os questionamentos norteadores foram elaborados a partir do fornecimento das fórmulas estruturais dos agrotóxicos mais citados (Cuprogarb, Folicur, Decis, Vertimec e Assist):

Que tipo de ligações entre carbonos encontramos nas fórmulas?

Quais funções orgânicas estão presentes nas fórmulas das substâncias?

Que relações podemos estabelecer entre tais funções e o fato de essas substâncias serem agrotóxicos?

Que relações podemos estabelecer entre a presença de tais funções e o nome científico dessas substâncias?

Quais radicais orgânicos encontramos? 
Como interpretamos as informações presentes nos rótulos das embalagens desses produtos?

Quais desses produtos são solúveis em água? Por quê?

Quantos têm presença de benzeno? Que particularidade a substância vai apresentar com essa presença?

Há presença de carbonos quirais nas fórmulas?

Qual a ordem dos carbonos encontrados? Qual a fórmula molecular?

Como seria classificada cada uma das cadeias?

3º A disciplina de Matemática seria contemplada com o trabalho de síntese, já realizado com os dados levantados, e com o estudo das prováveis funções que as variáveis envolvidas na pesquisa poderiam representar, tais como:

Equação matemática da relação entre as variáveis "quantidade de produtores" por "área de plantio";

Utilizar a matemática financeira para prever, a partir dos valores financiados, e ainda considerando o gasto médio de manutenção da lavoura por um ano, qual seria a área (total) estimada de plantio e a produção, em kg de maracujá, no período de janeiro a dezembro, estimando também o capital gerado por ela com o kg sendo vendido a $R \$ 0,40$;

Pesquisar preços de adubos e agrotóxicos em outras agropecuárias, inclusive em outras cidades, e apresentar gráficos que relacionassem um mesmo produto com diferentes preços, estimando percentualmente a economia envolvida, recomendando os resultados aos produtores.

\section{A contradição do orgânico}

Diante do retrato evidenciado pelas condições de produção de 29 agricultores, dentre os 32 entrevistados que utilizavam produtos químicos em sua cultura de maracujá, propomos aos alunos, como efetivação do confronto proposto, uma visita ao sítio de um agricultor orgânico.

As principais questões levantadas pelos estudantes que referenciam o confronto apareceram nos questionamentos sobre adubação do solo, controle de insetos e combate a fungos. Para realizar a adubação, o agricultor entrevistado respondeu que utilizava esterco de gado e resíduos das próprias frutas que produzia. Como o leite era a sua cultura de sobrevivência, antes da fruticultura, ele ainda possuía o gado, agora não mais leiteiro, mas de engorda, que lhe fornecia o esterco e não deixava sua área de pasto ociosa. Segundo esse agricultor, a única vacina que fornecia ao gado era contra a aftosa, pois contra carrapatos utilizava solução caseira à base de álcool e ninho, uma planta que tem função de repelente.

Seu inseticida é uma armadilha, feita com melado (ou solução com água e mel) que fica exposto e pendurado nas árvores frutíferas dentro de uma garrafa pet cortada ao meio. Segundo ele, alguns insetos (os de sangue frio) não têm sentido de satisfação ao se alimentar e comem até morrer. Esse produtor ainda utiliza outro inseticida natural, chamado de caldo sulfocálcico, que ele mesmo fabrica utilizando fumo, alho, pimenta, álcool e sabão neutro. Como fungicida, utiliza o caldo bordalesa, admitindo que sua pulverização resolve qualquer ataque às folhas e aos frutos do maracujá.

Sua mão de obra é familiar, como em quase 100\% dos casos entrevistados. Nesse sítio trabalham marido e mulher, mais dois filhos adolescentes, estudantes do Ensino Médio. Nenhum deles precisava polinizar, pois seu plantio foi realizado em área de reflorestamento, em local propício a ninhos de mamangavas (com muitas madeiras ocas) e essas abelhas davam conta do trabalho de polinização de todo seu maracujá.

Apesar de sócio da cooperativa, resolveu não vender seu produto in natura para ela. Optou por beneficiar em polpas de 100 gramas, que eram comercializadas a $\mathrm{R} \$ 0,60$ cada, quando buscadas em sua casa. Admitiu que seu lucro líquido mensal, incluindo as outras frutas que tinha, chegava a $\mathrm{R} \$ 3.000,00$. E disse estar muito satisfeito com seu negócio.

\section{Considerações finais}

Esta abordagem mereceu nossa reflexão por se tratar de uma forma de condução do processo de ensino-aprendizagem que defendemos, em que a escola, uma vez inserida em um determinado lócus, deve assumir como responsabilidade a intervenção social nas questões inerentes à vida das pessoas do lugar, no sentido de 
melhorá-la, dando significado ao conceito de educação institucional.

Recomendamos que outros conceitos presentes, e não considerados na abordagem, como a epistemologia dos caldos bordalesa e sulfocálcico, utilizados no controle de fungos e de insetos pelo agricultor orgânico, devam compor problemáticas para levar o estudante a entender, cada vez mais, as possibilidades que o conhecimento pode oferecer à sua vida.

A condução do processo em etapas, onde uma só se definia a partir dos acontecimentos da outra, imediatamente anterior, deu a esta abordagem um status de reflexiva. Segundo Freire (2000, p. 29), existem condições nas quais ensinar e aprender criticamente é possível; “[...] essas condições implicam ou exigem a presença de educadores e de educandos criadores, instigadores, inquietos, rigorosamente curiosos, humildes e persistentes". Todos esses adjetivos compõem qualidades presentes nos sujeitos da atividade. Moreira (1997, p.16), ainda nos lembra que:

Para aprender significativamente, o aluno tem que manifestar uma disposição para relacionar, de maneira não-arbitrária e não-literal (substantiva), à sua estrutura cognitiva, os significados que capta a respeito dos materiais educativos, potencialmente significativos, do currículo.

Em uma abordagem contextual, a arbitrariedade dos significados será menor, pois a ancoragem da nova informação terá seu status aumentado pela existência desse contexto. Ao trabalhar a fórmula de um agrotóxico, por exemplo, o aluno pode estar querendo saber até que ponto ela compromete a vida do agricultor que ele conhece e isso facilita seu envolvimento nesse trabalho.

Não foi a incerteza da próxima etapa o que mais nos preocupou como professores, mas sim qual caminho trilhar para encontrar as respostas, pois todos estavam questionando e sendo movidos por esses questionamentos. Nesse caminho, destacamos, por exemplo, as visitas, que contribuíram "[...] de forma a permitir ao aluno construir uma percepção significativa da realidade em que vive" (PCN+, p. 83).

Como professores por muitos anos, admitimos que ainda hoje a área de Ciências e Matemática frustra estudantes quanto à receptividade das disciplinas que a compõem e pela forma como é trabalhada, totalmente desvinculada de contextos da própria realidade dos es- tudantes. A experiência nos assegura de várias coisas, dentre elas:

Como é ineficiente, do ponto de vista cognitivo, lidar continuamente com eventos de maneira isolada. Os conceitos tornam possível a aquisição de idéias abstratas na ausência de experiências empírico-concretas e de idéias que podem ser usadas tanto para categorizar novas situações como para servir de pontos de ancoragem para assimilação e descoberta de novos conhecimentos (MOREIRA; MASINI, 1982, p. 28).

Como gostar então de Química, Física, Biologia e Matemática se o conhecimento oferecido a partir dessas disciplinas não transcende da sua condição abstrata de existir?

Para Ausubel, aprendizagem significa organização e integração do material na estrutura cognitiva. [...] A aprendizagem significativa processase quando o material novo, idéias e informações que apresentam uma estrutura lógica, interage com conceitos relevantes e inclusivos, claros e disponíveis na estrutura cognitiva, sendo por eles assimilados, contribuindo para sua diferenciação, elaboração e estabilidade. (MOREIRA; MASINI, 1982, p. 4).

Entendemos que cada pessoa que ensina imprime formas particulares, inclusive metodológicas, que irão definir as suas estratégias para que o aprendizado seja, ou não, alcançado. Consideramos que o contexto é um elemento aplicável em muitas situações no ensino de Ciências e Matemática e o recomendamos a todos os professores, mesmo concordando que não se encerra nele as possibilidades de uma boa aprendizagem.

\section{Agradecimentos}

À Coordenação de Aperfeiçoamento de Pessoal de Nível Superior (CAPES), pelo apoio financeiro.

\section{Referências}

CESCON, M. I.; PRETTI, E. C. S.; MOREIRA, F. Tema gerador e Pedagogia da Alternância: uma abordagem sócio-histórica. In: SIMPÓSIO NACIONAL DE GEOGRAFIA AGRÁRIA, 3., 2005, Presidente Prudente. Anais ... Presidente Prudente: UNESP, 2005.

FREIRE, P. Pedagogia da autonomia: saberes necessários à prática educativa. São Paulo: Paz e Terra, 2000. 
HERNANDES, T. et al. Manejo sanitário do rebanho leiteiro e resíduos de inseticidas piretroides em leite de vaca produzido no município de Chapada dos Guimarães, Brasil. Revista Acta Scientiae Veterinariae, v. 37, n. 2, p. 171-176, 2009.

MELLO, G. J. Ensino de Física para o ensino médio na educação do campo: aplicação dos conceitos físicos no cotidiano rural. Pontal do Araguaia. 2008. $87 \mathrm{f}$. Monografia (Graduação) - Universidade Federal de Mato Grosso, Pontal do Araguaia, 2008.

MOREIRA, M. A., CABALLERO, M. C.; RODRÍGUEZ, M. L. (Org.). Actas del Encuentro Internacional sobre el Aprendizaje Significativo. España: Editora Universidad de Burgos, 1997.

MOREIRA, M. A.; MASINI, E. F. S. Aprendizagem significativa: a teoria de David Ausubel. São Paulo: Moraes, 1982.

MORTIMER, E. F. Linguagem e formação de conceitos no ensino de ciências. Belo Horizonte: UFMG, 2000.
NASCIMENTO, L. M. J. Ler as palavras, ler o mundo. Paulo Freire: A utopia do saber. Viver mente e cérebro: coleção memória da pedagogia, v. 4, p. 38-41, 2005.

PALMA, D. C. A. Agrotóxicos em leite humano de mães residentes em Lucas do Rio Verde - MT. 2011. $103 \mathrm{f}$. Dissertação (Mestrado) - Instituto de Saúde Coletiva, Universidade Federal de Mato Grosso, Cuiabá, 2011.

PARAMETROS CURRICULARES NACIONAIS + ENSINO MÉDIO. Secretaria de Educação Média e Tecnológica. Orientações educacionais complementares aos parâmetros curriculares nacionais: Ciências da natureza, matemática e suas tecnologias. Brasília: MEC, 2002.

SIQUEIRA, S. L.; KRUSE, M. H. L. Agrotóxicos e saúde humana: contribuição dos profissionais do campo da saúde. Revista da Escola de Enfermagem da USP, v. 42, n. 3, p. 584-590, 2008.

VYGOTSKY, L. S. Pensamento e linguagem. 4. ed. São Paulo: Martins Fontes, 2008. 